\title{
EL RECLUTAMIENTO FORZADO DE MENORES DE EDAD EN LA PRENSA COLOMBIANA
}

Forced recruitment of children in the Colombian press.

Paula Valeria Gallo

Pauvunidad@gmail.com

María Angélica García garciangelica@outlook.com

Juliana Castellanos Díaz

jcastell@poligran.edu.co

Semillero: Pensar el periodismo haciendo periodismo Unidad de Investigación Periodística Institución Universitaria Politécnico Grancolombiano Programa Comunicación Social- Periodismo

Colombia

\section{Resumen}

Este artículo recoge la primera etapa de una investigación que analiza las representaciones mediáticas que se construyeron sobre el reclutamiento de menores de edad durante el proceso de paz entre el gobierno de Juan Manuel Santos y las Fuerzas Armadas Revolucionarias de Colombia (Farc). Para tal fin se seleccionaron el periódico El Tiempo y la Revista Semana, dos medios de alto impacto en la agenda nacional. La revisión se hizo a partir del análisis de contenido de todas las publicaciones que cada uno de los medios nombrados produjo entre agosto de 2012 y noviembre de 2016. Tras la revisión se concluye que el país carece de representaciones mediáticas sólidas sobre el hecho victimizante conocido como reclutamiento de menores de edad, debido a que el tema no ocupa un lugar primordial en las agendas mediáticas.

\section{Palabras claves:}

Reclutamiento de menores, representaciones mediáticas, cubrimiento, proceso de paz, conflicto armado, Farc. 
Introducción

El proceso de paz que el gobierno desarrolló con las Fuerzas Armadas Revolucionarias de Colombia (Farc), ha dado lugar a la discusión, poco frecuente, sobre la vinculación de menores de edad en las filas de esta estructura armada. Esa discusión no se ha dado con suficiente fuerza, no solo por la falta de interés de los gobiernos, sino también porque los medios de comunicación no suelen colocar el tema en sus agendas. Por consiguiente, es un fenómeno invisibilizado (Barajas, 2016; Hernández, 2016; Ruiloba, 2014).

Por lo tanto, es importante la construcción de un proyecto académico que consolide una ruta a través de la cual se comprenda la razones que han llevado a que en el siglo XXI este siga siendo un asunto menor para los gobiernos, pese a la complejidad que guarda en tanto evidencia un estado fallido que ha permitido la violación a los Derechos Humanos de niños, niñas y adolescentes.

Esta ponencia pretende analizar cómo el reclutamiento de menores fue representado en la prensa nacional periódico El Tiempo y la revista Semana- entre el año 2012 y 2016, tiempo en el que se desarrolló el proceso de paz entre el gobierno de Juan Manuel Santos y las Fuerzas Armadas Revolucionarias de Colombia (Farc)

\section{Contexto histórico}

Los dos procesos de desarme y desmovilización que se han dado en Colombia a lo largo del siglo XXI con las Autodefensas Unidas de Colombia (Auc) y las Fuerzas Revolucionarias de Colombia (Farc), han dado lugar a la apertura de telones de la historia del país, oculta en las filas de estas estructuras armadas ilegales. Las Auc desvelaron sus rostros, posturas y crímenes entre noviembre de 2002 y marzo de 2006, bajo un polémico acuerdo liderado por el gobierno de Álvaro Uribe Vélez. Las Farc, la guerrilla más antigua de América Latina, firmó en noviembre de 2016 un proceso de paz contenido en 7 acuerdos que conducen al país a transitar hacia un periodo de posconflicto, cuya etapa inicial ha permitido ahondar en el conocimiento de sus integrantes, estructuras y forma de acción por más de 50 años.

Entre las revelaciones que se han dado a la luz de esos procesos se encuentra la vinculación de menores de edad a las filas de estas estructuras armadas. Solo bajo las desmovilizaciones de los grupos ilegales el país ha logrado dimensionar la magnitud de este acto violento(Huesa, Romero, \& Muñoz, 2016; Mendoza, 2016; Moreno-López, Sánchez-Torres, Pérez-Raigoso, \& Alfonso-Solano, 2020).

En Colombia se entiende por este delito “la vinculación permanente o transitoria de personas menores de 18 años a grupos armados organizados al margen de la ley y/o grupos delictivos organizados, que se lleva a cabo por la fuerza, por engaño o debido a condiciones personales o del contexto" (Unida de Victimas, 2014. pp. 89).

Esta forma de victimización es transversal a la mayoría de los conflictos armados del mundo (Daza-Orozco, 2019). Por tal razón, en 1997 Graca Machel, defensora internacional de la infancia, entregó un estudio encomendado por el secretario general de las Naciones Unidas, Boutros-Ghali, titulado Repercusiones de los conflictos armados sobre los niños. El informe escandalizó a todos los gobiernos, incluyendo al de Colombia, carente hasta entonces de políticas claras para la atención de los menores que hacían parte de los grupos guerrilleros y paramilitares

Como consecuencia, en 1999 se oficializó en el país el programa Atención especializada para el restablecimiento de derechos de niñas, niños y adolescentes víctimas de reclutamiento ilícito, que se han desvinculado de grupos armados organizados, liderado por el Instituto Colombiano de Bienestar Familiar (ICBF). Desde ese año y hasta septiembre de 2019 el ICBF ha atendido a 6.715 menores. De ellos el 38.6\% ingresó al programa con 17 años, el $28 \%$ a los 16 , el $16.8 \%$ a los 15, el $8.8 \%$ entró a los 14, y el 9\% ingresó entre los 11 y los 13 años (información entregada por el ICBF a la Unidad de Investigación Periodística del Politécnico Grancolombiano).

Sin embargo, los números oficiales restringen la magnitud de menores reclutados en tanto que muchos de ellos no ingresaron al programa. El caso más dramático se presentó en la desmovilización de las Auc, proceso 
en el que el tema se dejó por fuera de los puntos acordados. Álvaro Villarraga, investigador del Centro Nacional de Memoria Histórica, explica:

En las desmovilizaciones colectivas de los paramilitares de las Autodefensas Unidas de Colombia (Auc) y grupos similares (...) se estima que solo un $10 \%$ de los niños, niñas y adolescentes reclutados fueron legalizados y vinculados al programa del ICBF, mientras que la gran mayoría fue oculta en su proceso de desvinculación por pate de mandos paramilitares (...) con anuencia de algunos funcionarios oficiales" (En Gonzales Uribe. 2016, p. 14).

Hilda Molano, coordinadora de la secretaría técnica de la Coalición contra la vinculación de niños, niñas y jóvenes al conflicto armado en Colombia (Coalico), y garante del proceso de entrega de menores en el marco del acuerdo de paz con las Farc, señala que:

En 2007 pedimos una audiencia ante la Corte Interamericana de Derechos Humanos, porque las AUC no entregaron a los niños que esperábamos. Contábamos con 4 menores por cada 20 combatientes, y de un promedio de 35 mil desmovilizados, quedaron aproximadamente 1.500 menores. En consecuencia, nos planteamos tres hipótesis, todas comprobadas: unos habrían sido devueltos a sus casas. Otros habían sido asesinados. Y quedarín algunos que serían la base de los grupos armados que aparecerían después (entrevista personal, 2 de agosto de 2017).

No obstante, en las negociaciones que iniciaron el 26 de agosto de 2012 en la Habana- Cuba, entre el gobierno de Juan Manuel Santos y las Farc, el asunto de los menores reclutados fue un punto central de la agenda. Por tal razón la organización armada entregó entre septiembre de 2016 y septiembre de 2017, de acuerdo con información que dio a los medios de comunicación Paula Gaviria, entonces alta consejera para los Derechos Humanos, 124 menores.

Los organismos internacionales garantes de los derechos de los menores esperaban un número más alto, debido a que las Farc ha sido históricamente el grupo armado que más menores ha reclutado. Sin embargo, muchos adolescentes alcanzaron la mayoría de edad a lo largo del proceso, y otros, cuya cifra se desconoce, se negaron a abandonar al grupo armado, a pesar de encontrarse en el proceso de desarme y desmovilización.

\section{Postura teórica: los medios constructores de representaciones mediáticas}

Para adentrarse en el aspecto mediático, la presente investigación se nutre de la apuesta epistemológica de Manuel Martín Serrano. De acuerdo con Rubirá y Martínez (2017), Martín-Serrano "ha trabajado con bastante frecuencia las representaciones como componentes del sistema de comunicación. Junto con los actores, las expresiones y los instrumentos, éstas son parte del modelo dialéctico para el estudio de los sistemas de comunicación" (p.154).

Desde la Teoría de la Producción Social de la Comunicación de Martín Serrano, se asume que: La comunicación pública provee a los miembros de la comunidad de relatos (escritos, orales, imágenes) en los que se les propone una interpretación del entorno (material, social, ideal) y de lo que en él acontece. (...) Desde la perspectiva de su posible influencia cognitiva, la comunicación pública es una de las actividades que intervienen en la socialización de las gentes. (...) Por eso, la producción de representaciones del mundo puede ser indistintamente examinada como el inicio o como la culminación de algún cambio social (2009. P.40).

El sociólogo alemán Niklas Luhmann plantea que "los medios de masas construyen realidad (...). Los medios permiten, sin prueba consistente, la ilusión de una realidad accesible al conocimiento" (2000, p. 132). Por lo tanto, la producción que hacen los periodistas no puede simplificarse a la mera información, pues trasciende la construcción de representaciones mediáticas que, en conjunto con otros elementos, como las experiencias directas sobre los fenómenos dan lugar a las representaciones sociales desde las que los integrantes de un grupo se reconocen y reconocen a los otros. Esto implica entender que, a partir de esas representaciones, los individuos construyen simbólicamente la realidad en la que están inmersos(E. Norman-Acevedo, 2018).

Por consiguiente, Martín Serrano expone que las representaciones son producto del tránsito que se da desde el nivel existencial, donde se transforma el entorno, al nivel cognitivo, donde se modifica el conocimiento sobre el mundo (2009, p. 159-166). Explica que los acontecimientos pertenecen a un Sistema de Referencia 
(donde suceden las cosas), y la forma como se comprende lo que allí ocurre corresponde al Sistema Cognitivo de cada sujeto (donde se estructuran y modifican las representaciones de los acontecimientos).

Nos enfrentamos a dos macroprocesos que dan lugar a las representaciones mediáticas: el primero lo ejecuta el periodista cuando elige un acontecer del sistema de referencia, y de él selecciona unos datos -Martín Serrano los nomina Datos de Referencia- que posteriormente convierte en estructuras sígnicas para dar forma a un relato. En ese proceso media su Sistema Cognitivo, en el que interviene su historia de vida, conocimientos, creencias. Y es a partir de este último sistema que selecciona el acontecer y lo que mostrará de él en un tipo de narrativa (visual, sonora, escrita, multimedia, audiovisual)(Dos Santos Amaro Elías; Nogales Bocio, Antonia Isabel; Pérez Calle, Begoña; Pérez Lagos, Camila; Marta-Lazo, Carmen; Barredo Ibáñez, Daniel; De La Garza Montemayor, Daniel Javier; Murcia Quiñones, Harvey; Gil Quintana, J, Jenny Juliana, 2019).

El segundo momento corresponde a los usuarios de la información, para quienes los relatos periodísticos son un universo de datos de la realidad que contienen implícitamente representaciones del acontecer que son aceptadas, rechazadas o que complementan las construidas previamente. Posteriormente, con ese material simbólico, los sujetos crean, transforman, deciden y actúan sobre sus entornos.

"Conviene insistir en la indeterminación que tiene el tránsito desde el universo del acontecer al universo del conocer -y viceversa- (...) La comunicación, sea cara a cara o institucionalizada, siempre se propone reducir en alguna medida esa indeterminación, de forma explícita o implícita" (Martín Serrano, 1986. p. 109). Sobre esta cuestión Luhmann dice que:

La tesis del constructivismo operativo no conduce a una negación del mundo y no discute que no haya realidad. Sin embargo, no presupone que el mundo sea un objeto, sino más bien lo considera como lo reflexionó ya la fenomenología; como horizonte inalcanzable. Por esta razón no existe otra posibilidad que la de construir la realidad (2000, p. 8).

El rol periodístico trasciende de la recolección de datos del entorno, a la interpretación de ellos y la delimitación que desde allí se impone a la realidad. En ello se sustenta su poder. Se trata, sin embargo, de un poder compartido con otras formas de comunicación. "Esa representación personal de la realidad raramente será atribuible al efecto exclusivo de la información obtenida por el actor receptor a través de los medios de comunicación. Las otras fuentes de información suelen aportar sus datos" (Martín Serrano. 2009, p. 136). Esas otras fuentes son nominadas por Martín Serrano como la experiencia del pasado y del presente, la observación directa del acontecimiento y los datos que le llegan a través de la interacción cara a cara (2009, p.135).

Desde una postura sociocognitiva, Teun A. van Diijk (1997) habla de modelos mentales construidos a partir de los sistemas de comunicación en los que está inmerso un sujeto, los cuales se estructuran a partir de los datos que vienen de los medios de comunicación. "Un modelo es una representación (en el segmento episódico de la memoria a largo plazo) de una experiencia, es decir, desde que un actor social observa un evento, participa en él o lee/oye acerca del mismo" (p. 230-233). Los medios, entonces, llevan esos modelos del estadio personal al general, para validarlos o normalizarlos, de forma que conducen a un tipo de aceptación o rechazo.

En esta línea, Martín Serrano plantea que los relatos periodísticos contienen implícita o explícitamente representaciones de los acontecimientos a través de las que intentan dar un orden a la realidad (2009, p. 138). No obstante, todos los medios consolidan representaciones diferentes por cuenta del tipo de aconteceres que seleccionan, de los datos de referencia que obtienen y de la forma que dan a sus relatos. Incluso cuando convergen en la selección de aconteceres, las representaciones pueden variar. Sobre esto Luhmann afirma que:

Los medios de comunicación en todos sus campos programáticos (el autor se refiere a formatos y géneros) no se dirigen a la construcción de una realidad consensuada; cada vez que lo pretenden resulta sin éxito. Lo que su mundo contiene y produce es la diversidad de opiniones a lo largo y a lo ancho (...) Lo definitivo son los temas y no las opiniones (2000, p. 101).

Los medios, como instituciones adscritas a unos universos culturales particulares, buscan la reproducción continua de las normas y valores que cada grupo se esfuerza en preservar, transformar o implementar. Esto 
es posible a través de la relación que se establece constantemente entre normas-valores e información periodística. Martín Serrano nombra esta función como Mitificación, sustancial para comprender las representaciones mediáticas que se forjan sobre el reclutamiento de menores:

Los datos de referencia incluidos en el producto comunicativo mencionan a determinados Sujetos, concernidos de una u otra forma por el acontecer, que asumen la función de personaje del relato. (...) El personaje en el desempeño de cada rol (frente a otros- frente a su contexto) puede y suele estar descrito con determinados atributos (físicos, sociales y morales, etc.) (2009, p. 209-210).

La Mitificación confirma que los medios elaboran unas formas de entendimiento de la realidad a partir de quienes -como sujetos- les dan cuerpo a los acontecimientos que en ella se producen. Por consiguiente, los datos de referencia también alimentan las construcciones que los periodistas hacen sobre los personajes, entendidos como fuentes de orden testimonial, oficial, expertos etc; o como otros sociales, es decir, de quienes se habla en el relato, pero cuyas posturas o discursos no se mencionan; "son una especie de participantes ausentes" (van Dijk. 2000, p.283).

En conclusión, los periodistas son parte sustancial del ecosistema comunicativo desde el que se estructuran representaciones mediáticas que, consumidas por los usuarios de la información y sumadas a las representaciones que llegan de otras fuentes, dan lugar a las representaciones sociales desde las que se ordena, nombra y delimita la realidad. Por ello, han dicho Rey y Barbero (1997), que el periodismo es un espacio de escenificación de lo social tanto por los hechos que presenta como por la manera como los presenta.

En consecuencia, es pertinente comprender el lugar que ocupa el reclutamiento de menores de edad en la prensa nacional -periódico El Tiempo y revista Semana- entre el año 2012 y 2016, para comprender de forma global si es un asunto del que se generan representaciones mediáticas.

\section{Metodología}

Para cumplir con el objetivo planteado, se desarrolló un análisis de contenido de las publicaciones realizadas sobre el reclutamiento de menores entre agosto de 2012 y noviembre de 2016, periodo en el que tuvo lugar el proceso de paz con las Farc.

El estudio se hizo mediante un análisis del periódico de mayor circulación nacional: El Tiempo; y la revista de análisis político más importante del país: Revista Semana. Ambos medios se revisaron tanto en su edición digital como en la física. Vale la pena aclarar que ambos medios tienen distinta periodicidad. El primero es diario, el segundo semanal, lo que no afecta el objetivo de esta investigación.

La metodología, comprendida desde el planteamiento de José Luis Piñuel, se entiende como:

"el conjunto de procedimientos interpretativos de productos comunicativos que proceden de procesos singulares de comunicación previamente registrados, y que, basados en técnicas de medida, a veces cuantitativas (estadísticas basadas en el recuento de unidades), a veces cualitativas (lógicas basadas en la combinación de categorías) tienen por objeto elaborar y procesar datos relevantes sobre las condiciones mismas en que se han producido aquellos textos (Piñuel, 2002, p. 2).

Bajo esta metodología se revisaron 341 artículos de los medios señalados.

Resultados

Entre agosto de 2012 y noviembre de 2016 el periódico El Tiempo publicó 234 artículos sobre el reclutamiento de menores de edad por grupos armados ilegales; la revista Semana publicó 107.

El Tiempo presentó un crecimiento en la publicación de artículos sobre el tema entre el año 2014 y 2016 al pasar de 40 publicaciones a 70 respectivamente. La revista Semana tuvo un auge de artículos sobre la temática en 2014 con 33 artículos, baja en 2015 a 19, y en 2016 presenta nuevamente un aumento al presentar 27 artículos. 
No debe desconocerse que 2016 es justamente el año en el que se da la discusión en la Habana de la necesidad de que las Farc entregue a los menores reclutados que, a la fecha, estaban en sus filas. En septiembre de ese año el grupo entrega 124 menores, lo que se convierte en un tema de agenda mediática.

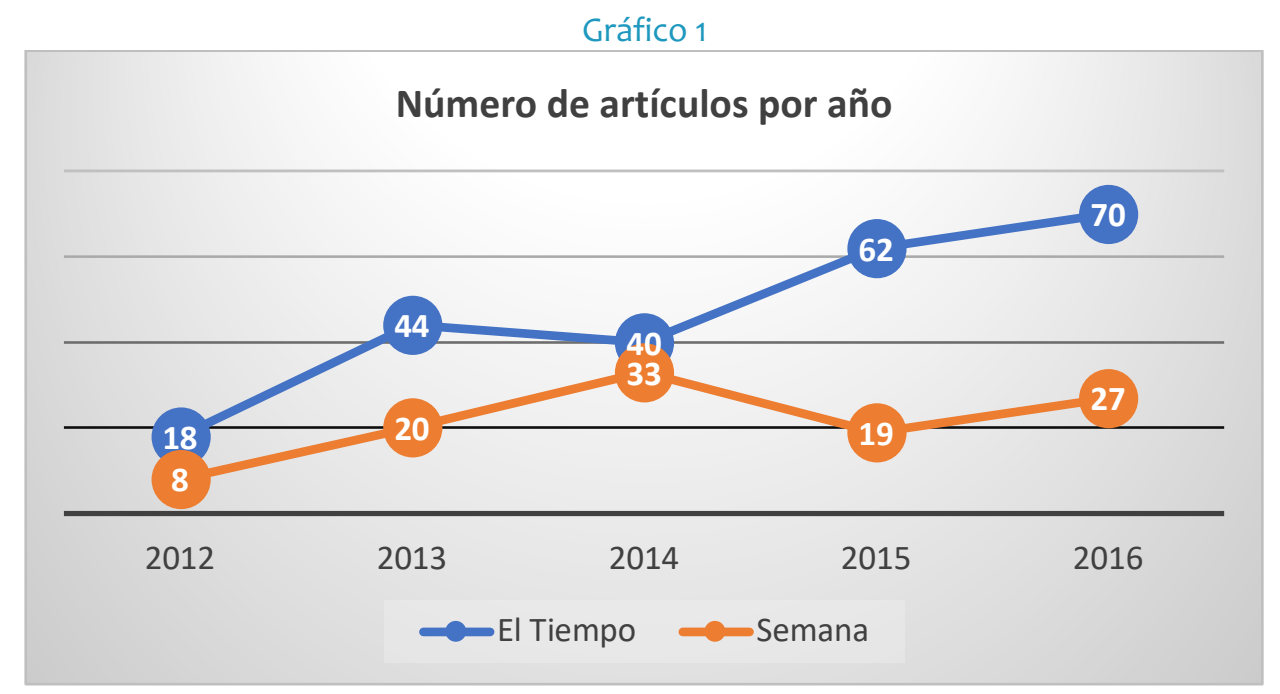

Fuente: elaboración propia

Pese a lo expuesto, es necesario señalar que, si bien se presentó durante el proceso de paz con las Farc un aumento en la publicación de artículos sobre el reclutamiento de menores, no siempre el tema era el objeto central de los artículos. Entre 2012 y 2014, los primeros dos años del proceso, el reclutamiento de menores apareció como un subtema dentro de los artículos que generalmente hablaban de las conversaciones de paz y los grupos armados.

No obstante, el asunto cobra relevancia en 2016 por la discusión que se da principalmente por los críticos del proceso y la oposición, de la necesidad de suspender los diálogos con las Farc si no entregaban a los menores que estaban en sus filas, tal como se evidencia en el gráfico 1.

De esta manera se encuentra que en 2013 El Tiempo publicó 32 artículos en los que el reclutamiento era un subtema, mientras que la revista Semana publicó 15 artículos en los que el reclutamiento ocupaba un segundo lugar. La tendencia permanece en 2015 en tanto se pasar a 26 artículos de El Tiempo y 13 de la revista Semana. Es decir, el reclutamiento de menores ha ocupado un lugar pobre en la agenda mediática no solo por la escasa visibilidad que se da al problema, sino porque hay periodos en los que aparece solo como un tema secundario dentro de sus relatos.

Gráfico 2

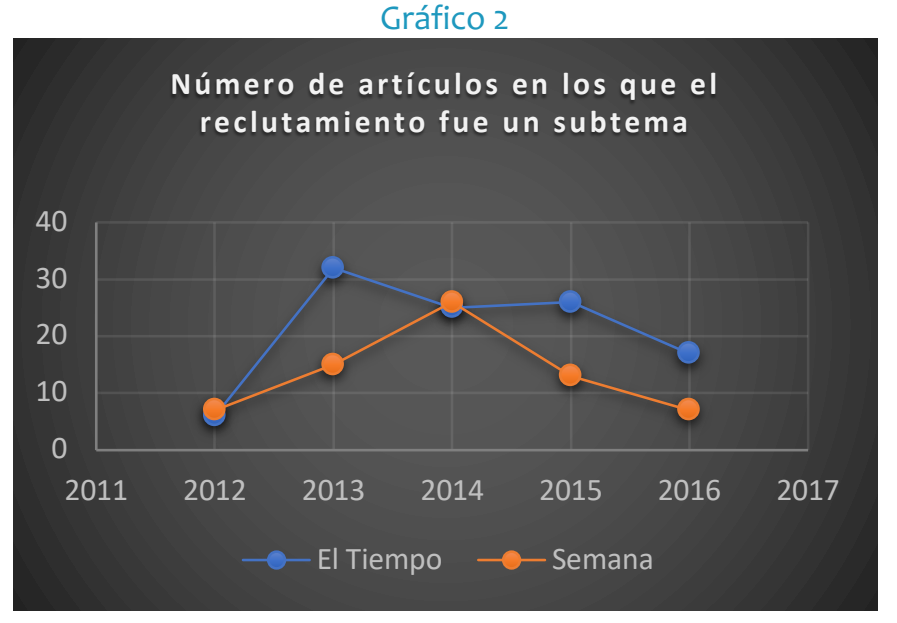


En coherencia con lo anterior, el asunto del reclutamiento de menores de edad por grupos armados ilegales se va convirtiendo en tema central entre 2015 y 2016. De esta forma se encuentra que El Tiempo publica 36 artículos en 2015 y 53 en 2016 sobre el fenómeno en cuestión, y como asunto principal de los relatos; y la revista Semana publica 6 artículos en 2015 y 20 en 2016.

Confirmando así que 2016 fue el año en el que más se publicaron artículos en los que el reclutamiento de menores por parte de grupos armados ilegales era el objeto de referencia central para los periodistas.

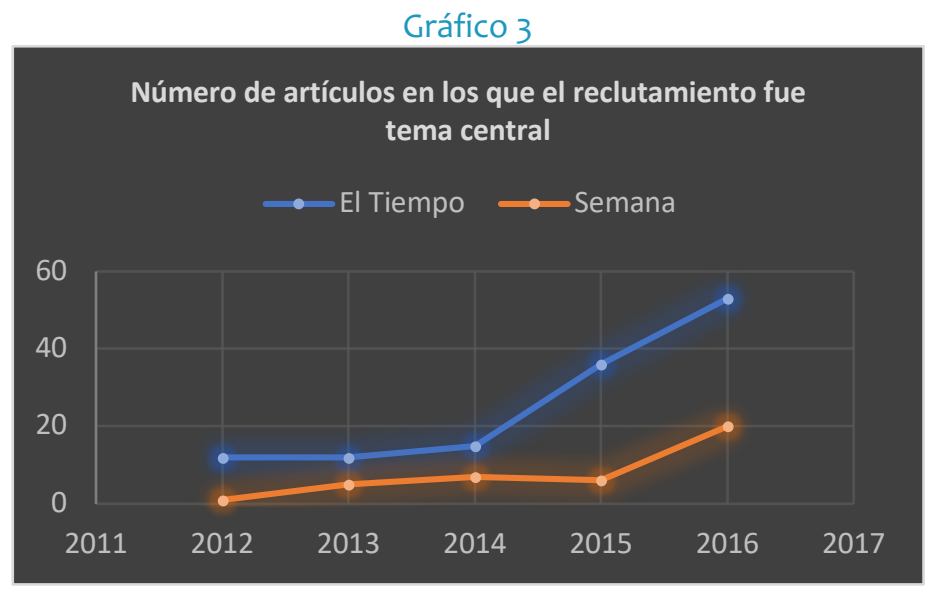

Fuente: elaboración propia

Es importante mencionar que a pesar de la visibilidad que gana el tema del reclutamiento forzado en Colombia entre los años 2015 y 2016, el fenómeno no logra dimensionarse en sus justas proporciones por cuenta de la dificultad que tienen los periodistas para acceder a los menores víctimas de este flagelo. Pero también, se evidencia en los artículos revisados un interés por plantear el tema desde lo político más que desde la violación a derechos fundamentales de niños, niñas y adolescentes, o de las responsabilidades que le caben en este delito tanto a los grupos armados ilegales como al Estado.

Para comprender este fenómeno se necesitan los testimonios de los menores, esto es, sus historias de vida, porque solo con ello el país podrá dimensionar cómo se produjo el reclutamiento, cuáles eran las condiciones de vida al momento de ser reclutados, cómo era el entorno de esos menores desde lo social, lo político y lo económico, categorías fundamentales para que un país comprenda todas las dimensiones de un hecho victimizante.

Lo expuesto se sustenta en que de los 234 artículos publicados por el periódico El Tiempo entre agosto de 2012 y noviembre de 2016, solo 41 artículos llevan fuentes testimoniales. En el caso de la Revista Semana se encuentra que, de los 107 artículos publicados en el mismo periodo, solo 12 contienen fuentes testimoniales. 


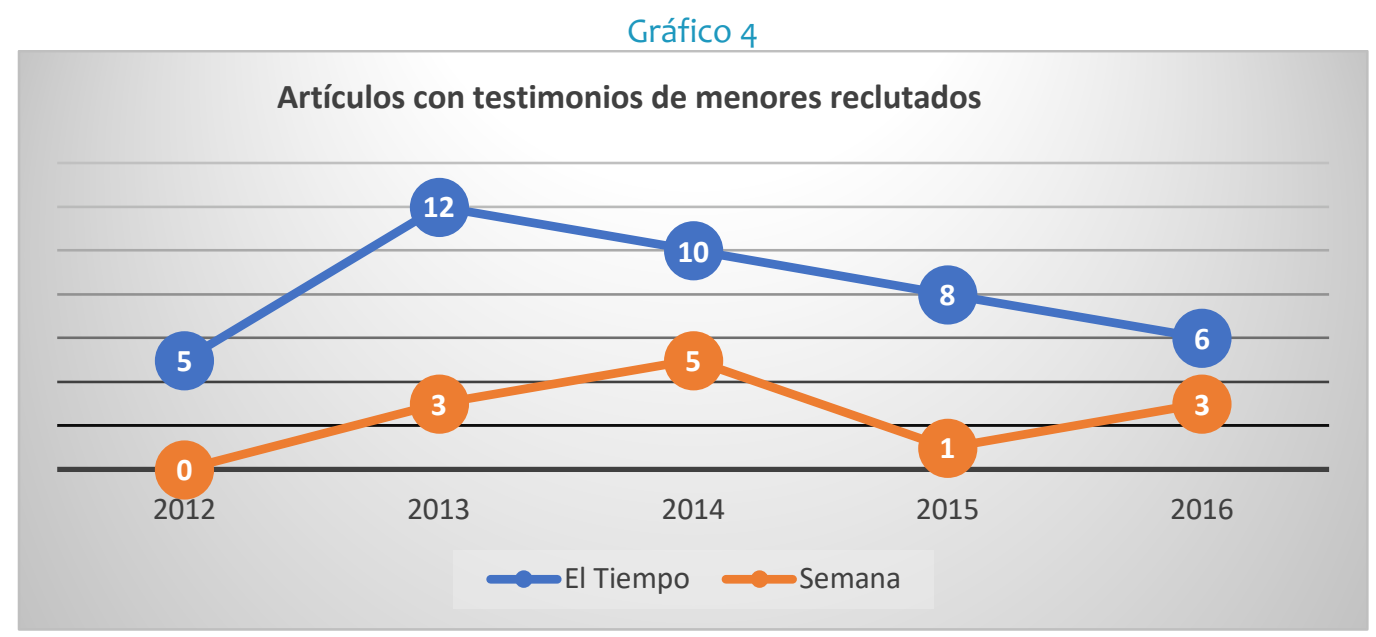

Fuente: elaboración propia

\section{Conclusiones y discusión}

Los resultados presentados evidencian que el reclutamiento de menores de edad en el país careció, durante el proceso de paz que se llevó a cabo con las Farc, de un lugar relevante en las agendas mediáticas de dos de los medios más importantes del país, la revista Semana y el periódico El Tiempo, en el periodo 2012 -2016. Por lo tanto, cuantitativamente la producción de artículos para la construcción de representaciones mediáticas es pobre, lo que conduce a asumir, en esta etapa de la investigación, que las representaciones sobre ese fenómeno propio del conflicto armado son básicas, es decir, la opinión pública sabe que el problema existe, pero no conoce en profundidad las características de este.

Lo anterior se sustenta no solo por la baja publicación de artículos a lo largo de cuatro años: 234 El Tiempo, y 107 la revista Semana. Sino porque esos números no corresponde a publicaciones en los que el tema fuera el objeto central de los relatos. Así se encuentra que del número de textos que sacó el periódico 134 obedecen a publicaciones en los que el reclutamiento era un subtema. Así mismo, del número de publicaciones de la revista, 39 corresponden artículos en los que el tema en cuestión solo fue un tema de segunda línea. Cabe explicar que como tema secundario en muchos de esos artículos la cuestión no paso de ser únicamente nombrada.

No obstante, hay un año en el que el tema cobró relevancia: 2016. Tal como se expuso en los resultados, durante ese año los políticos que se oponían al proceso exigieron que se declinara el proyecto de paz si las Farc no entregaba a todos los menores que estaba a esa fecha en sus filas. El asunto, entonces, se volvió tema de debate nacional, lo que generó un aumento visible en las publicaciones sobre el fenómeno del reclutamiento como tema central. Las Farc cumplió entregó a 124 menores, lo que hizo que el proceso continuara mientras que el tema volvía a perderse en la maraña informativa nacional, aunque el fenómeno continuara.

En este escenario las representaciones mediáticas que se produjeron sobre el reclutamiento de menores de edad se estructuraron con las Farc como la organización más victimizante. Sin embargo, no se construyen representaciones que evidencien la responsabilidad que también tiene el Estado tras la no garantía de derechos fundamentales y protección a los menores campesinos, lo que se fundamenta en causa principal del reclutamiento según Coalico.

De esta manera, la primera etapa de la investigación que acá se presenta evidencia que el país carece de representaciones mediáticas sólidas sobre el hecho victimizante conocido como reclutamiento de menores de edad, debido a que el tema no ocupa un lugar primordial en las agendas mediáticas, y que en los pocos periodos en los que el interés de los periodistas aumenta sobre el fenómeno está ligado más al uso estratégico y político que le dan los gobernantes que por una preocupación real para que ese flagelo termine. 


\section{Referencias bibliográficas}

Luhmann, Niklas (2000). La realidad de los medios de masas. México: Anthropos editorial.

Martín Barbero, Jesús. Rey Beltrán, Germán. (1997). “El Periodismo en Colombia: de los oficios y los medios”. Signo y Pensamiento 6 (30), 13-30.

Martín Serrano, M (1986). La producción social de comunicación. Madrid: Alianza.

Martín Serrano, M (2009). La producción social de comunicación. Madrid: Alianza.

Piñuel, José Luis (2002). “Epistemología, metodología y técnicas del análisis de contenido. Revista Estudios de Sociolingüística 3 (1), 142. Recuperado de: https://www.ucm.es/data/cont/docs/268-2013-07-29Pinuel Raigada AnalisisContenido 2002 EstudiosSociolinguisticaUVigo.pdf

Rubira, Rainer. Puebla, Belén (2017). “Representaciones sociales y comunicación: apuntes teóricos para un diálogo interdisciplinar inconcluso". Convergencia Revista de Ciencias Sociales. 25 (76). 147-167. https://doi.org/10.29101/crcs.v25i76.4590

Unidad Nacional de Víctimas. Recuperado de: https://www.unidadvictimas.gov.co/es/publicaciones-periodicas/15760

Van Dijk, Teo (2000). Ideología, una aproximación multidisciplinaria. Barcelona: Gedisa. 